\title{
Disparities in clinical and demographic characteristics among Asian/Pacific Islander and Non-Hispanic White newly diagnosed lung cancer patients
}

Parth Bhargav Patel ( $\sim$ parth.patel@icahn.mssm.edu )

Icahn School of Medicine at Mount Sinai Department of Thoracic Surgery https://orcid.org/0000-0002-3694-9213

Naomi Alpert

Icahn School of Medicine at Mount Sinai Institute for Translational Epidemiology

Emanuela Taioli

Icahn School of Medicine at Mount Sinai Institute for Translational Epidemiology

Raja Flores

Icahn School of Medicine at Mount Sinai Department of Thoracic Surgery

\section{Research Article}

Keywords: Lung Cancer, Racial Disparities, Asian/Pacific Islanders, Minority Populations, Administrative Database

Posted Date: March 2nd, 2021

DOI: https://doi.org/10.21203/rs.3.rs-188271/v1

License: () (1) This work is licensed under a Creative Commons Attribution 4.0 International License. Read Full License

Version of Record: A version of this preprint was published at Cancer Causes \& Control on January 19th, 2022. See the published version at https://doi.org/10.1007/s10552-021-01548-5. 


\section{Abstract \\ Purpose}

Racial disparities persist among lung cancer (LC) patients but have not been adequately studied among Asian/Pacific Islander (API) subgroups, which are heterogeneous. This study compared clinical and demographic characteristics at diagnosis of API subgroups and NHW patients.

\section{Methods}

NHW and API adults diagnosed with LC were identified from the Surveillance, Epidemiology, and End Results database (1990-2015). API was divided into 8 subgroups: Filipino, Chinese, Japanese, Asian Indian/Pakistani, Korean, Vietnamese, Hawaiian/Pacific Islander, and Other. Multivariable multinomial logistic regression models were used to assess independent associations of clinical and demographic factors with API/subgroup.

\section{Results}

There were 522,702 (92.6\%) NHW and 41,479 (7.4\%) API LC patients. API were significantly younger (OR adj: $0.53,95 \%$ Cl: $0.49-0.58$ for $\geq 80$ vs. $\leq 39$ years) than NHW. All subgroups followed a similar trend except Japanese patients. API and subgroups were less often female (OR adj: $0.84,95 \%$ Cl: $0.83-0.86)$, and unmarried ( $\mathrm{OR}_{\mathrm{adj}}$ : $\left.0.71,95 \% \mathrm{Cl}: 0.69-0.74\right)$, except for Hawaiian/Pacific Islanders who were more often unmarried. API and subgroups were more frequently diagnosed at a later stage ( $\mathrm{OR}_{\mathrm{adj}}: 1.31,95 \% \mathrm{Cl}: 1.27-1.35$ for stage IV vs. stage I). API had significantly less squamous cell carcinoma (OR $\mathrm{adj}$ : $0.54,95 \% \mathrm{Cl}$ : 0.52-0.55, compared to adenocarcinoma), with varying effects by subgroup. (range: $\mathrm{OR}_{\mathrm{adj}}\left[\right.$ Vietnamese]: 0.37 to $\mathrm{OR}_{\mathrm{adj}}$ [Hawaiian/Pacific Islander]: 0.89 ).

\section{Conclusion}

At diagnosis, there are significant differences in demographic and clinical characteristics between NHW, API, and API subgroups. Treating API patients as a single population may overlook biological, environmental and behavioral differences that might be beneficial in designing prevention strategies and treatment.

\section{Introduction}

Lung and bronchial cancer is among the leading causes of cancer death in the United States[1-3]. The standard of care for treating lung cancer often includes surgery, radiotherapy, and/or chemotherapy. Despite a decrease in the incidence in lung cancer in recent years, racial disparities in disease stage at diagnosis, treatment, and survival continue to persist $[4,5]$.

Disparities by race have been well documented among Non-Hispanic Whites (NHW), Blacks/African Americans, Hispanics, and Asian Americans and Pacific Islanders (API) [1, 3, 5-8]. However, few studies have assessed these differences among API ethnic subgroups [9-12].

As one of the fastest growing populations in the US, API displays immense heterogeneity, especially when it comes to country of origin, cultural diversity, health behaviors, health outcomes, lifestyle, and socioeconomic status $[9,10]$. This heterogeneity is likewise seen in how the burden of lung cancer is distributed across the API ethnic subgroups (ES) $[1,9,11]$. For example, Chang et al. reported that Japanese lung cancer patients in California had significantly worse overall and disease-specific survival rates compared to their Chinese counterparts [12]. Despite the heterogeneity across ES, API patients are frequently treated as one group in research, primarily due to small sample size restrictions [10].

The goal of this study was to assess differences in demographic and clinicopathologic characteristics at lung or bronchial cancer diagnosis between API, ES, and NHW patients. This study drew upon data for NHW and API patients diagnosed with lung and bronchial cancer between from January 1,1990 and December 31, 2015 from the Surveillance, Epidemiology, and End Results (SEER) Program. The primary aims of this analysis were to identify racial disparities at the time of diagnosis and to determine whether these disparities persisted after adjusting for confounders.

\section{Methods}

\section{Data Source and Study Population}

SEER is a program funded by the National Cancer Institute $(\mathrm{NCl})$ that compiles cancer incidence and survival information from population based registries, which cover approximately $35 \%$ of the population of the United States[13]The database provides data on patient demographics, primary cancer diagnoses, tumor morphology, cancer stage at diagnosis, treatment, and vital status[14]. The dataset is public and de-identified and therefore the study was deemed exempt from institutional review.

For this study, the SEER*Stat software[15] was used to query the SEER 18 registry for all patients diagnosed with lung or bronchial cancer from $1990-2015$ (n $=1,011,282$ ). NHW and API adults ( $\geq 18$ years) with a microscopically confirmed first or only primary diagnosis of lung or bronchial cancer and a reporting source other than autopsy or death certificate were included $(n=575,126)$. Cases were excluded if only malignant cells in secretions were present, no primary tumor was found, tumor histology was coded as either sarcoma or unspecified malignant neoplasm, or patient underwent surgery of regional and/or distant site/nodes only, as the clinical characterization of these patients was less clear. This resulted in a cohort of 564,181 cases (Fig. 1). 
The study population was divided according to race, into NHW and the overall API groups. Based on prior research, API patients were further divided into eight major ethnic subgroups (ES) as follows,: Chinese, Japanese, Filipino, Hawaiian/Pacific Islander (including Hawaiian, Samoan, Pacific Islander, Tongan, Fijian, Guamanian, Micronesian, Polynesian, Melanesian, Chamorro, Tahitian, Kampuchean, and New Guinean), Korean, Vietnamese, Asian Indian/Pakistani, and Other (which comprised of Laotian, Hmong, Thai, and Other/Unknown API)[11]

\section{Covariates}

Variables of interest included age at diagnosis, sex, marital status, TNM stage, tumor size, tumor grade, and histology. TNM stage was classified using the third (1990-2003) and sixth (2004-2015) editions of the American Joint Cancer Committee on Cancer. Histology was categorized as adenocarcinoma, squamous cell, large cell, other specified non-small cell, (which includes carcinoid tumors, adenoid cystic, mucoepidermoid, adenosquamous, and large cell neuroendocrine carcinomas), non-small cell - not otherwise specified (NOS), and small cell carcinomas according to the guidelines by the International Agency for Research on Cancer[16].

\section{Statistical Analysis}

NHW and API patients (both the overall group, and the eight ES) were compared across all demographic and clinicopathologic characteristics using $\chi^{2}$ tests. Multivariable logistic regression was used to assess the independent association of all covariates with race (API vs. NHW), using odds ratios (OR) and $95 \%$ confidence intervals $(\mathrm{Cl})$. A multivariable multinomial logistic regression was performed to assess the independent associations between these characteristics and race, using all 8 API ES.

Multivariable analyses were adjusted for age at diagnosis, sex, marital status, TNM stage, and histology. In order to account for changes over time, models were also adjusted for year of diagnosis. Multivariable analyses were conducted on the subset of patients with complete data for the included variables. Because $11.9 \%$ of patients were missing stage, a missing category for stage was created, so as not to exclude these patients.

Although tumor size and grade were provided as part of baseline patient characteristics, they were not included in the regression models. As tumor size overlaps with TNM staging[17], we only included TNM stage, as it is the more comprehensive measure. Grade was excluded from regression analysis as it was missing for nearly half of the study population ( $45.8 \%$ vs. $46.2 \%$ for NHW vs. overall API), limiting the potential to draw any meaningful conclusions.

All analyses were conducted using SPSS version 26 . In all analyses, $p<0.05$ was considered statistically significant.

\section{Results}

There were 564,181 patients included in the study; 522,702 (92.6\%) NHW and 41,479 (7.4\%) API patients (Table 1). Compared to NHW patients, the overall API group was significantly younger, more often male, married, diagnosed at a later stage, with a larger tumor size, and more likely to have well differentiated tumors, and an adenocarcinoma histology (all $p<0.0001$ ). 
Table 1

Demographics of Non-Hispanic White and Asian Pacific Islander Patients Diagnosed with Lung or Bronchial Cancer $(n=$ 564,181).

\begin{tabular}{|c|c|c|c|c|c|c|}
\hline & & \multicolumn{2}{|c|}{$\begin{array}{l}\text { Non-Hispanic White } \\
(n=522,702)\end{array}$} & \multicolumn{2}{|c|}{$\begin{array}{l}\text { Asian/Pacific Islander } \\
(n=41,479)\end{array}$} & \multirow[t]{2}{*}{$\mathrm{p}$-value } \\
\hline Variable & & $\mathrm{n}(\%)$ & & $\mathrm{n}(\%)$ & & \\
\hline \multicolumn{7}{|c|}{ Age (years) } \\
\hline & $\leq 39$ & 3,673 & $(0.7)$ & 656 & $(1.6)$ & $<.0001$ \\
\hline & $40-49$ & 23,945 & $(4.6)$ & 2,383 & (5.7) & \\
\hline & $50-59$ & 86,830 & $(16.6)$ & 6,725 & $(16.2)$ & \\
\hline & $60-69$ & 163,412 & (31.3) & 11,858 & $(28.6)$ & \\
\hline & $70-79$ & 169,556 & $(32.4)$ & 13,136 & $(31.7)$ & \\
\hline & $\geq 80$ & 75,286 & $(14.4)$ & 6,721 & $(16.2)$ & \\
\hline \multicolumn{7}{|l|}{ Sex } \\
\hline & Male & 281,388 & $(53.8)$ & 24,621 & $(59.4)$ & $<.0001$ \\
\hline & Female & 241,314 & $(46.2)$ & 16,858 & $(40.6)$ & \\
\hline \multicolumn{7}{|c|}{ Martial Status } \\
\hline & Married/ & 285,009 & $(54.5)$ & 27,401 & $(66.1)$ & $<.0001$ \\
\hline & Domestic Partner & & & & & \\
\hline & Never Married & 53,637 & $(10.3)$ & 3,763 & (9.1) & \\
\hline & Previously Married & 164,593 & $(31.5)$ & 9,105 & $(22.0)$ & \\
\hline & Unknown & 19,463 & (3.7) & 1,210 & $(2.9)$ & \\
\hline \multicolumn{7}{|c|}{ TNM Stage } \\
\hline & I & 89,179 & $(17.1)$ & 6,348 & $(15.3)$ & $<.0001$ \\
\hline & II & 19,482 & (3.7) & 1,366 & (3.3) & \\
\hline & III & 129,670 & $(24.8)$ & 10,758 & $(25.9)$ & \\
\hline & IV & 221,352 & $(42.3)$ & 18,906 & $(45.6)$ & \\
\hline & Unknown & 63,019 & $(12.1)$ & 4,101 & (9.9) & \\
\hline \multicolumn{7}{|c|}{ Tumor Size $(\mathrm{cm})$} \\
\hline & $<1$ & 6,267 & $(1.2)$ & 375 & $(0.9)$ & $<.0001$ \\
\hline & $1.0-1.9$ & 47,853 & $(9.2)$ & 3,016 & (7.3) & \\
\hline & $2.0-2.9$ & 70,483 & $(13.5)$ & 5,608 & $(13.5)$ & \\
\hline & $3.0-3.9$ & 63,751 & $(12.2)$ & 5,584 & $(13.5)$ & \\
\hline & $4.0-4.9$ & 50,613 & $(9.7)$ & 4,408 & $(10.6)$ & \\
\hline & $5.0-5.9$ & 40,077 & $(7.7)$ & 3,400 & $(8.2)$ & \\
\hline & $\geq 6$ & 89,611 & $(17.1)$ & 7,307 & $(17.6)$ & \\
\hline & Diffuse (lobe or lung) & 839 & $(0.2)$ & 96 & $(0.2)$ & \\
\hline & Unknown & 153,208 & $(29.3)$ & 11,685 & $(28.2)$ & \\
\hline \multicolumn{7}{|l|}{ Grade } \\
\hline & Well-Differentiated & 23,093 & $(4.4)$ & 2,190 & (5.3) & $<.0001$ \\
\hline & Moderately Differentiated & 77,158 & $(14.8)$ & 6,798 & $(16.4)$ & \\
\hline & Poorly Differentiated & 142,052 & $(27.2)$ & 11,234 & $(27.1)$ & \\
\hline & Undifferentiated & 41,231 & $(7.9)$ & 2,100 & (5.1) & \\
\hline & Unknown & 239,168 & $(45.8)$ & 19,157 & $(46.2)$ & \\
\hline Histology & & & & & & \\
\hline
\end{tabular}




\begin{tabular}{|c|c|c|c|c|c|}
\hline \multirow[b]{2}{*}{ Adenocarcinoma } & \multicolumn{2}{|c|}{$\begin{array}{l}\text { Non-Hispanic White } \\
(n=522,702)\end{array}$} & \multicolumn{2}{|c|}{$\begin{array}{l}\text { Asian/Pacific Islander } \\
(n=41,479)\end{array}$} & \multirow{2}{*}{$\begin{array}{l}\mathrm{p} \text { - value } \\
<.0001\end{array}$} \\
\hline & 197,363 & $(37.8)$ & 21,922 & $(52.9)$ & \\
\hline Squamous & 115,845 & $(22.2)$ & 6,835 & $(16.5)$ & \\
\hline Large Cell & 47,667 & $(9.1)$ & 3,759 & $(9.1)$ & \\
\hline Other Specified Malignant Carcinoma & 18,556 & $(3.6)$ & 1,098 & $(2.6)$ & \\
\hline Non-Small Cell, NOS & 51,471 & $(9.8)$ & 3,805 & $(9.2)$ & \\
\hline Small Cell & 91,800 & $(17.6)$ & 4,060 & $(9.8)$ & \\
\hline
\end{tabular}

Within the overall API population, there were 9,860 (23.8\%) Chinese, 5,832 (14.1\%) Japanese, 10,002 (24.1\%) Filipino, 4,178 (10.1\%) Hawaiian/Pacific Islander, 2,928 (7.1\%) Korean, 4,041 (9.7\%) Vietnamese, 1,522 (3.7\%) Asian Indian/Pakistani, and 3,116 (7.5\%) Other API patients (Table 2). The API ES were significantly different on all variables (all $p<0.0001)$. Japanese and Chinese patients were significantly older than other ES $(24.1 \%$ and $20.9 \% \geq 80$ years, compared to $8.4-15.2 \%$ for other ES), while Asian Indian/Pakistani, Filipino, and Vietnamese patients were the least likely to be female (32.4\%, $37.2 \%$ and $34.9 \%$, compared to $41.1-47.2 \%$ for all other ES). Chinese patients were the most likely to be married (70.4\%), while Hawaiian/Pacific Islanders were the least (53.3\%). Korean and Hawaiian patients were the most likely to have squamous cell carcinoma (21.8\% and $21.4 \%)$. While all API ES were more likely to be diagnosed at a later stage, compared to NHW patients, Vietnamese and Asian Indian/Pakistani patients were the most like to present at stage IV (49.4\% and $47.7 \%$, compared to $42-46.5 \%$ for all other ES). 
Table 2

Demographics of Asian/Pacific Islander Patients Diagnosed with Lung or Bronchial Cancer $(n=564,181)$.

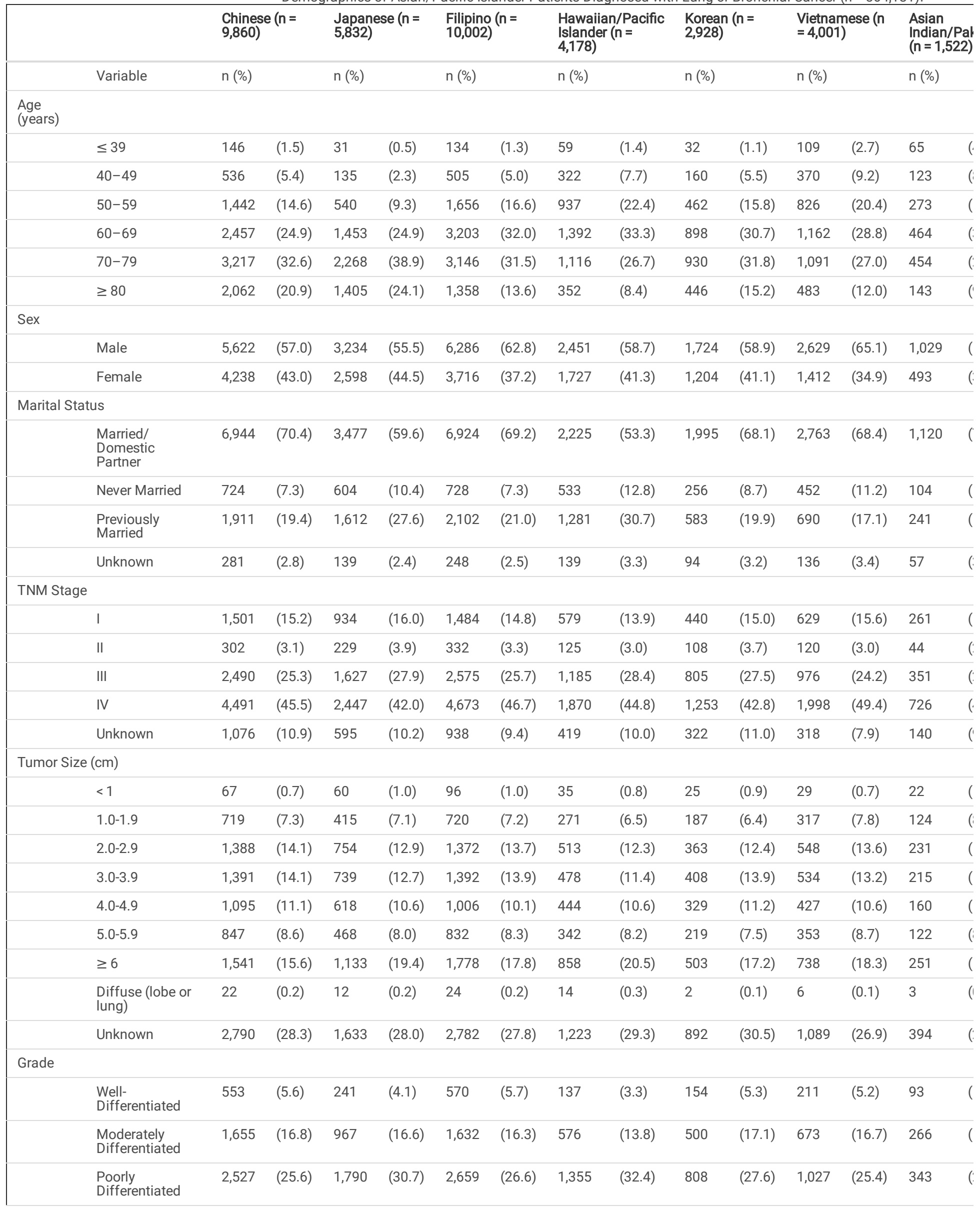




\begin{tabular}{|c|c|c|c|c|c|c|c|c|c|c|c|c|c|c|c|}
\hline & \multirow[b]{2}{*}{ Undifferentiated } & \multicolumn{2}{|c|}{$\begin{array}{l}\text { Chinese }(n= \\
9,860)\end{array}$} & \multicolumn{2}{|c|}{$\begin{array}{l}\text { Japanese }(n= \\
5,832)\end{array}$} & \multicolumn{2}{|c|}{$\begin{array}{l}\text { Filipino }(n= \\
10,002)\end{array}$} & \multicolumn{2}{|c|}{$\begin{array}{l}\text { Hawaiian/Pacific } \\
\text { Islander }(n= \\
4,178)\end{array}$} & \multicolumn{2}{|c|}{$\begin{array}{l}\text { Korean }(n= \\
2,928)\end{array}$} & \multicolumn{2}{|c|}{$\begin{array}{l}\text { Vietnamese ( } n \\
=4,001)\end{array}$} & \multicolumn{2}{|c|}{$\begin{array}{l}\text { Asian } \\
\text { Indian/Pal } \\
(n=1,522)\end{array}$} \\
\hline & & 423 & (4.3) & 400 & (6.9) & 475 & $(4.7)$ & 270 & (6.5) & 186 & $(6.4)$ & 180 & $(4.5)$ & 58 & ( \\
\hline & Unknown & 4,702 & $(47.7)$ & 2,434 & $(41.7)$ & 4,666 & $(46.7)$ & 1,840 & $(44.0)$ & 1,280 & $(43.7)$ & 1,950 & $(48.3)$ & 762 & ( \\
\hline \multicolumn{16}{|l|}{ Histology } \\
\hline & Adenocarcinoma & 5,737 & $(58.2)$ & 2,580 & $(44.2)$ & 5,415 & $(54.1)$ & 1,727 & (41.3) & 1,374 & $(46.9)$ & 2,452 & $(60.7)$ & 834 & ( \\
\hline & Squamous Cell & 1,295 & $(13.1)$ & 1,187 & $(20.4)$ & 1,657 & $(16.6)$ & 893 & $(21.4)$ & 638 & $(21.8)$ & 504 & $(12.5)$ & 240 & ( \\
\hline & Large Cell & 986 & $(10.0)$ & 643 & $(11.0)$ & 862 & (8.6) & 450 & $(10.8)$ & 237 & $(8.1)$ & 281 & (7.0) & 85 & ( \\
\hline & $\begin{array}{l}\text { Other Specified } \\
\text { Malignant } \\
\text { Carcinoma }\end{array}$ & 238 & (2.4) & 158 & $(2.7)$ & 255 & (2.5) & 112 & $(2.7)$ & 63 & $(2.2)$ & 98 & $(2.4)$ & 78 & ( \\
\hline & $\begin{array}{l}\text { Non-Small Cell, } \\
\text { NOS }\end{array}$ & 911 & $(9.2)$ & 513 & (8.8) & 894 & (8.9) & 370 & (8.9) & 231 & $(7.9)$ & 428 & $(10.6)$ & 143 & (' \\
\hline & Small Cell & 693 & (7.0) & 751 & (12.9) & 919 & (9.2) & 626 & (15.0) & 385 & (13.1) & 278 & $(6.9)$ & 142 & \\
\hline
\end{tabular}

\section{Demographics}

In the multivariable analysis comparing overall API to NHW patients, (Table 3), API patients were significantly younger $\left(\mathrm{OR}_{\text {adj: }}: 0.53,95 \% \mathrm{Cl}: 0.48-0.58 \mathrm{for} \geq 80\right.$ vs. $\leq 39$ years). They were also less likely to be female ( $\mathrm{OR}_{\mathrm{adj}}$ : $\left.0.85,95 \% \mathrm{Cl}: 0.83-0.86\right)$. When compared to NHW patients, the API population was significantly

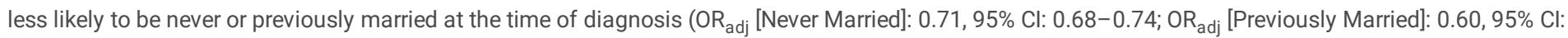
0.58-0.61). 
Independent Associations of Clinical and Demographic Characteristics with Asian/Pacific Islander Ethnicity $(\mathrm{n}=$ $543,508)$.

\begin{tabular}{|c|c|c|}
\hline \multicolumn{2}{|l|}{ Variable } & $\begin{array}{l}\text { API vs. NHW } \\
\text { Adjusted OR }(95 \% \mathrm{Cl}) *\end{array}$ \\
\hline \multicolumn{3}{|c|}{ Age (years) } \\
\hline & $\leq 39$ & 1.00 (ref) \\
\hline & $40-49$ & $0.54(0.49-0.59)$ \\
\hline & $50-59$ & $0.42(0.38-0.46)$ \\
\hline & $60-69$ & $0.40(0.36-0.43)$ \\
\hline & $70-79$ & $0.44(0.41-0.48)$ \\
\hline & $\geq 80$ & $0.53(0.48-0.58)$ \\
\hline \multicolumn{3}{|l|}{ Sex } \\
\hline & Female vs. Male & $0.85(0.83-0.86)$ \\
\hline \multicolumn{3}{|c|}{ Marital Status } \\
\hline & Married/Domestic Partner & 1.00 (Ref) \\
\hline & Never Married & $0.71(0.68-0.74)$ \\
\hline & Previously Married & $0.60(0.58-0.61)$ \\
\hline \multicolumn{3}{|c|}{ TNM Stage } \\
\hline & 1 & 1.00 (Ref) \\
\hline & II & $1.05(0.98-1.11)$ \\
\hline & III & $1.31(1.27-1.36)$ \\
\hline & IV & $1.31(1.27-1.35)$ \\
\hline & Unknown & $1.11(1.06-1.16)$ \\
\hline \multicolumn{3}{|c|}{ Histology } \\
\hline & Adenocarcinoma & 1.00 (Ref) \\
\hline & Squamous & $0.54(0.52-0.56)$ \\
\hline & Large Cell & $0.71(0.69-0.74)$ \\
\hline & Other Specified Malignant Carcinoma & $0.52(0.49-0.56)$ \\
\hline & Non-Small Cell, NOS & $0.69(0.66-0.71)$ \\
\hline & Small Cell & $0.40(0.39-0.41)$ \\
\hline
\end{tabular}

Although in many cases the trends of the associations remained similar across the eight API ES, the magnitude of the associations varied, when comparing individual ES to NHW patients (Table 4). Among API ES, Chinese, Filipino, Hawaiian/Pacific Islander, Korean, Vietnamese, Asian Indian/Pakistani, and Other API patients were significantly younger compared to NHW (range of effects: $\mathrm{OR}_{\text {adj }}$ [Asian Indian/Pakistani]: $0.10,95 \% \mathrm{Cl}: 0.07-0.13$ for $\geq 80$ vs. $\leq 39$ years; $\mathrm{OR}_{\mathrm{adj}}$ [Chinese]: $0.79,95 \% \mathrm{Cl}: 0.66-0.94$ for $\geq 80 \mathrm{vs}$. $\leq 39$ years). Japanese patients did not follow this trend and were more likely to be diagnosed with lung or bronchial cancer at an older age ( $\mathrm{OR}_{\text {adj }}$ [Japanese]: $2.84,95 \% \mathrm{Cl}: 1.96-4.12$ for $\geq 80 \mathrm{vs}$. $\leq 39$ years $)$.

When API patients were divided across ES, Filipino, Hawaiian/Pacific Islander, Korean, Vietnamese, and Asian Indian/Pakistani patients were significantly less likely to be female (range of effects: $\mathrm{OR}_{\mathrm{adj}}$ [Asian Indian/Pakistani]: 0.58, 95\% Cl: 0.52-0.65; OR adj [Korean]: 0.92, 95\% Cl: 0.85-0.99). Among Chinese, Japanese, and Other API patients, there was no significant difference in gender when compared to NHW patients in the odds of being female at time of

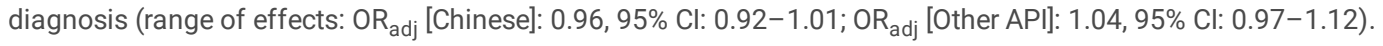

Chinese, Filipino, Korean, Vietnamese, Asian Indian/Pakistani, and Other API patients were significantly less likely to be never or previously married at diagnosis, compared to being married or in a domestic partnership (range of effects for never married: OR adj [Asian Indian/Pakistani]: 0.40, 95\% Cl: 0.33-0.49; $\mathrm{OR}_{\text {adj }}$ [Other API]: $0.83,95 \% \mathrm{Cl}: 0.74-0.94$; range of effects for previously married: OR adj [Chinese]: $0.45,95 \%$ Cl: $0.43-0.47 ; 0 R_{\text {adj }}$ [Other API]: 0.60, 95\% Cl: 0.55-0.66). Japanese patients were less likely to previously married then NHW patients, but there was no significant difference in the odds of being never married. Hawaiian/Pacific Islander patients were significantly more likely to be never married ( $\left.\mathrm{OR}_{\mathrm{adj}}: 1.15,95 \% \mathrm{Cl}: 1.05-1.27\right)$ and previously married at the time of diagnosis $\left(\mathrm{OR}_{\mathrm{adj}} 1.16,95 \% \mathrm{Cl}: 1.08-1.24\right)$. 


\section{Clinicopathologic Characteristics}

Overall, API patients were significantly more likely to be diagnosed at a later stage compared to NHW patients (OR adj: $1.31,95 \%$ Cl: $1.27-1.35$ for stage IV vs. stage I) (Table 3). They were also more likely to be diagnosed with adenocarcinoma and less likely to present with a histology of squamous cell, small cell, or large cell carcinoma (compared to adenocarcinoma: $\mathrm{OR}_{\mathrm{adj}}$ [squamous]: $0.54,95 \% \mathrm{Cl}$ : $0.52-0.56 ; \mathrm{OR}_{\mathrm{adj}}$ [small cell]: $0.40,95 \% \mathrm{Cl}$ : $0.39-0.41 ; 0 \mathrm{R}_{\mathrm{adj}}$ [large cell]: $0.71,95 \%$ Cl: 0.69-0.74).

Similar to demographics, these associations varied by API ES despite similar trends (Table 4). When examined separately, Chinese, Japanese, Filipino, Hawaiian/Pacific Islander, Korean, Vietnamese, and Other API patients were more likely to be diagnosed at both stage III and IV while this effect was only significant for stage IV for Asian Indian/Pakistani patients (range of effects for stage III vs. I: OR adj [Other API]: 1.20, 95\% Cl: 1.07-1.35; OR 95\% Cl: 1.26-1.60; range of effects for stage IV vs. I: OR adj [Asian Indian/Pakistani]: 1.17, 95\% Cl: 1.01-1.36; OR adj [Filipino]: 1.39, 95\% Cl: 1.31-1.48).

All API ES were significantly less likely than NHW patients to present with squamous histology, compared to adenocarcinoma (range of effects: $\mathrm{OR}_{\mathrm{adj}}$ [Chinese]: 0.39, 95\% Cl: 0.37-0.42; $\mathrm{OR}_{\text {adj }}$ [Hawaiian/Pacific Islander]: 0.90, 95\% Cl: 0.83-0.98). There were also large differences in the odds of large cell (range of effects: $\mathrm{OR}_{\mathrm{adj}}$ [Vietnamese]: $0.58,95 \% \mathrm{Cl}$ : 0.51-0.66; $\mathrm{OR}_{\mathrm{adj}}[$ Hawaiian/Pacific Islander]: 0.99, 95\% Cl: 0.89-1.10) and small cell ( range of effects: $\mathrm{OR}_{\mathrm{adj}}\left[\right.$ Vietnamese]: 0.25, 95\% Cl: 0.32-0.47; OR ${ }_{\mathrm{adj}}[\mathrm{Hawaiian/Pacific} \mathrm{Islander]:} \mathrm{0.72,} \mathrm{95 \%} \mathrm{Cl:} \mathrm{0.66-0.80)} \mathrm{histologies} \mathrm{by} \mathrm{ES.}$

\section{Discussion}

In this study, using the SEER database, we examined a cohort of 522,702 NHW and 41,479 API lung cancer patients across a 26-year period to identify demographic and clinicopathologic differences at the time of diagnosis. While lung and bronchial cancer has been well documented among the overall API population, individual API ethnic subgroups have not been adequately or extensively studied[10]. Despite growing evidence that the API population is highly heterogeneous, API patients from different ethnic subgroups continue to be studied as a single population entity, thus minimizing any differences in cultural diversity, health practices, lifestyle, health behaviors socioeconomic status, and health outcomes[1,9-12]. With limited precedent, this is one of the few studies that has examined lung and bronchial cancer among the following eight, heterogeneous API ethnic subgroups: Filipino, Chinese, Japanese, Asian Indian/Pakistani, Korean, Vietnamese, Hawaiian/Pacific Islander, and Other [1, 9-12].

Consistent with prior literature, we demonstrated that the overall API population is younger compared to NHW patients at the time of diagnosis[11, 18, 19]. When API patients were divided according to their ethnic subgroups, this trend was maintained across most ethnicities, but the magnitude of the association varied significantly. In particular, Chinese, Filipino, Hawaiian/Pacific Islander, Korean, and Asian Indian/Pakistani patients were all more likely to be diagnosed at a younger age compared to NHW patients. This was particularly prominent for Hawaiian/Pacific Islander, Vietnamese, and Asian Indian/Pakistani patients. Trends in age among Japanese patients did not mirror the overall API population. Instead, it was the only ethnic subgroup which was more likely to be diagnosed with lung cancer at older ages. A similarly large study of 849,088 patients with lung cancer from the SEER database showed that Hawaiian/Pacific Islander, Vietnamese, and Asian Indian/Pakistani patients having the youngest mean age at diagnosis with Japanese patients having the oldest age at diagnosis[11].

In addition, our study demonstrated ethnic variations in marital status. This is of particular importance, as this has been previously reported to be a significant predictor of survival among lung cancer patients. While the overall API group was more likely to be married than their NHW counterparts, this was not consistent across ethnic subgroups. The trend was particularly prominent among Chinese, Filipino, Korean, Vietnamese, and Asian Indian/Pakistani patients. However, marital status among Hawaiian/Pacific Islander patients did not mirror that of the overall API population. Rather, it was the only group who was more likely to be unmarried. Based on a study of 161,228 small and non-small cell lung cancer patients, being married and/or widowed at diagnosis were independent predictors of improved survival at diagnosis, attributed to the benefits of a social support system on health behaviors, access to healthcare, cancer treatment, and overall physical and mental well-being[20]. Taken together, the differences in marital status presented in this study provides insight into potential differences across ethnic subgroups in terms of social support systems, which may subsequently affect survival[20,21].

The current study also showed that all API patients were more likely than NHW patients to be diagnosed with adenocarcinoma and less likely to present with squamous cell, small cell, or large carcinomas. Chinese and Vietnamese patients were least likely to be diagnosed with small cell and squamous cell carcinomas, while Hawaiian/Pacific Islander patients, were most likely of the eight ethnic subgroups to present with these histologies. These findings are consistent with prior studies examining lung cancer tumor histology among API patients[18, 22-25]. According to an analysis of lung and bronchial cancer among API patients in California from 1988-2003 by Raz et. al, API patients, especially those from East and Southeast Asia have disproportionately higher risk for adenocarcinoma[22]. While the incidence of adenocarcinoma per 100,000 among the overall API population is 12.1, the incidence is 13.1 among the Chinese, 13.1 among Filipinos, and 17.1 among Vietnamese - the greatest among all API ethnic subgroups[22].

Taken together, the higher burden of adenocarcinoma paired with the younger age at diagnosis among API patients seem to suggest non-smoking related causes as drivers of lung cancer in this population[25-29]. In fact, the incidence of smoking among API patients from 2010-2013 is 10.9\% compared to 24.3\% for NHW[30]. The incidence is especially low among Chinese (7.6\%), Asian Indian (7.6\%), and Japanese Americans (10.2\%)[30]. Koo and Ho have corroborated this, by observing that in Asian populations, a younger age at diagnosis of lung cancer tends to occur in never-smokers[28]. One possible contributor to these findings might be the higher prevalence of epidermal growth factor (EGFR) mutations observed in the tumors of API patients diagnosed with lung cancer, which has been known an initiator and driver of primarily adenocarcinoma[11, 27, 28, 31-34]. The high rates of adenocarcinoma among Chinese and Vietnamese patients, which was observed in this study, correlates with the high overall EGFR mutation rate in these populations, which is 30.0$50.2 \%$ and $40.7-64.2 \%$, respectively $[11,23,35,36]$. 
We also demonstrated that the overall API population was more likely to present with advanced lung cancer (stage III and IV) compared to NHW patients. The advance presentation of lung cancer among most API patients, with variations among ethnic subgroups, might suggest that current US screening guidelines for lung cancer might not be appropriately detecting early stage lung cancer among all API patients. As reported by Kumar et al., the National Lung Screening Trial (NLST) screening criteria (screening with low-dose computed tomography (CT) among adults between the ages of 55-74 years with at least 30 pack-year smoking history and are currently smoking or have quit within the past 15 years) is valid among Asian patients despite comprising only $2 \%$ of the NLST population[37]. However, broadening of the original NLST screening criteria in both age and smoking history as put forth by the current U.S. Preventive Services Task Force (USPSTF) guidelines would not increase screening rates among Asian patients, as a significant portion of lung cancer occurs primarily in never or light smokers[37, 38]. Rather, given the high rates EGFR mutation among API patients, EGFR mutation analysis among never and light smokers can be a better alternative, since it might be as sensitive but more specific compared to CT in diagnosing lung cancer[37].

In conclusion, our study is one of the few large population studies that has examined lung and bronchial cancer among eight major API ethnic subgroups and spans a 26-year time period and 17 US cancer registries. While prior studies have simply assessed the distribution of demographic and clinicopathologic factors across API ethnic subgroups, this is the only study, based on our literature review, which has assessed the independent associations of these factors with race. Our study further reinforces the heterogeneity of the API population with lung and bronchial cancer. While analysis of API ethnic subgroups revealed largely similar trends in clinical and demographic factors, compared to the overall API population, there was significant variability among ethnic subgroups when individually studied. In other words, demographic and clinicopathologic characteristics significantly differ across subgroups, and none of the eight API ethnicities completely mirrored the overall API population. Ultimately, these findings indicate that treating API patients as a single population may miss crucial biological, environmental and behavioral differences. Instead, it may be beneficial to view these subgroups separately when developing strategies for prevention and efficacious treatment.

This study should be interpreted within the context of its limitations. This was a retrospective study using a population-based database that only contained pre-selected demographic and clinicopathologic variables. We did not have available data for smoking status, family history of lung and/or bronchial cancer, occupational exposure to carcinogens, and driver mutations, such as EGFR, which would provide increased insight into these populations. Furthermore, we did not have any information on their place of birth. It is highly likely that a significant portion of the API population was born and raised outside of the United States. This in turn can possibly affect their cultural, lifestyle, and behavioral practices in comparison to their counterparts who were born and primarily raised in the United States. Future research into these factors, as well as differences in survival among API patients is warranted. Despite limitations, this study contributes to our understanding of the heterogeneity of API patients with lung cancer and highlights how opportunities for better treatment and prevention strategies may be missed when these patients are treated as a single group.

\section{Declarations}

Funding No funds, grants, or other support was received.

Conflicts of Interest The authors have no conflicts of interest to declare that are relevant to the content of this article.

Availability of Data and Material Data was obtained from the public and de-identified Surveillance, Epidemiology, and End Results (SEER) database. The SEER*Stat software was used to query the SEER 18 registry for all patients diagnosed with lung or bronchial cancer from 1990-2015. All analyses were conducted using SPSS version 26. The study was deemed exempt from institutional review at the Icahn School of Medicine at Mount Sinai.

Authors' Contributions Study design and conception: all authors. Collection and assembly of data: Patel, Alpert, and Taioli. Statistical analysis and interpretation: all authors. Manuscript writing and final approval of manuscript: all authors.

\section{References}

1. Tannenbaum SL, Koru-Sengul T, Zhao W, Miao F, Byrne MM (2014) Survival disparities in non-small cell lung cancer by race, ethnicity, and socioeconomic status. Cancer J 20(4):237-245. doi:10.1097/ppo.0000000000000058

2. Tantraworasin A, Taioli E, Liu B, Flores RM, Kaufman AJ (2018) The influence of insurance type on stage at presentation, treatment, and survival between Asian American and non-Hispanic White lung cancer patients. Cancer Med 7(5):1612-1629. doi:10.1002/cam4.1331

3. Yang R, Cheung MC, Byrne MM, Huang Y, Nguyen D, Lally BE et al (2010) Do racial or socioeconomic disparities exist in lung cancer treatment? Cancer 116(10):2437-2447. doi:10.1002/cncr.24986

4. Siegel RL, Miller KD, Jemal A. Cancer statistics (2018) CA Cancer J Clin. 2018;68(1):7-30. doi: 10.3322/caac.21442

5. Wolf A, Alpert N, Tran BV, Liu B, Flores R, Taioli E (2019) Persistence of racial disparities in early-stage lung cancer treatment. J Thorac Cardiovasc Surg 157(4):1670-9.e4. doi:10.1016/j.jtcvs.2018.11.108

6. Mulligan CR, Meram AD, Proctor CD, Wu H, Zhu K, Marrogi AJ (2006) Unlimited access to care: effect on racial disparity and prognostic factors in lung cancer. Cancer Epidemiol Biomarkers Prev 15(1):25-31. doi:10.1158/1055-9965.epi-05-0537

7. Trinh QD, Nguyen PL, Leow JJ, Dalela D, Chao GF, Mahal BA et al (2015) Cancer-specific mortality of Asian Americans diagnosed with cancer: a nationwide population-based assessment. J Natl Cancer Inst 107(6):djv054. doi:10.1093/jnci/djv054

8. Wisnivesky JP, McGinn T, Henschke C, Hebert P, lannuzzi MC, Halm EA (2005) Ethnic disparities in the treatment of stage I non-small cell lung cancer. Am J Respir Crit Care Med 171(10):1158-1163. doi:10.1164/rccm.200411-14750C

9. Goggins WB, Wong G (2009) Cancer among Asian Indians/Pakistanis living in the United States: low incidence and generally above average survival. Cancer Causes Control 20(5):635-643. doi:10.1007/s10552-008-9275-x

Page $10 / 12$ 
10. Thompson CA, Gomez SL, Hastings KG, Kapphahn K, Yu P, Shariff-Marco S et al (2016) The Burden of Cancer in Asian Americans: A Report of National Mortality Trends by Asian Ethnicity. Cancer Epidemiol Biomarkers Prev 25(10):1371-1382. doi:10.1158/1055-9965.epi-16-0167

11. Li D, Du XL, Ren Y, Liu P, Li S, Yang J et al (2016) Comparative Analysis of Clinicopathologic Features of, Treatment in, and Survival of Americans with Lung or Bronchial Cancer. PLoS One 11(5):e0156617. doi:10.1371/journal.pone.0156617

12. Chang ET, Shema SJ, Wakelee HA, Clarke CA, Gomez SL (2009) Uncovering disparities in survival after non-small-cell lung cancer among Asian/Pacific Islander ethnic populations in California. Cancer Epidemiol Biomarkers Prev 18(8):2248-2255. doi:10.1158/1055-9965.epi-09-0332

13. Surveillance, Epidemiology, and End Results (SEER) Program (www.seer.cancer.gov). In: National Cancer Institute D, Surveillance Research Program, editor.1969-2015

14. Sun M, Trinh QD (2016) A Surveillance, Epidemiology and End Results (SEER) database malfunction: perceptions, pitfalls and verities. BJU Int 117(4):551-552. doi:10.1111/bju. 13226

15. SEER ^Stat software (seer.cancer.gov/seerstat). 8.3.5 ed: Surveillance Research Program, National Cancer Institute

16. Egevad L, Heanue M, Berney D, Fleming K, Ferlay J (2007) Histological groups. Cancer Incidence in Five Continents. IARC Scientific Publications No.160, Lyon, pp 61-66

17. Detterbeck FC (2018) The eighth edition TNM stage classification for lung cancer: What does it mean on main street? J Thorac Cardiovasc Surg 155(1):356-359. doi:10.1016/j.jtcvs.2017.08.138

18. Hamid MS, Shameem R, Gafoor K, George J, Mina B, Sullivan K (2015) Non-Small-Cell Lung Cancer Clinicopathologic Features and Survival Outcomes in Asian Pacific Islanders Residing in the United States: A SEER Analysis. J Cancer Epidemiol 2015:269304. doi:10.1155/2015/269304

19. Gomez SL, Chang ET, Shema SJ, Fish K, Sison JD, Reynolds P et al (2011) Survival following non-small cell lung cancer among Asian/Pacific Islander, Latina, and Non-Hispanic white women who have never smoked. Cancer Epidemiol Biomarkers Prev 20(3):545-554. doi:10.1158/1055-9965.EPI-10-0965

20. Tannenbaum SL, Zhao W, Koru-Sengul T, Miao F, Lee D, Byrne MM (2013) Marital status and its effect on lung cancer survival. Springerplus 2:504. doi:10.1186/2193-1801-2-504

21. Chen Z, Yin K, Zheng D, Gu J, Luo J, Wang S et al (2020) Marital status independently predicts non-small cell lung cancer survival: a propensity-adjusted SEER database analysis. J Cancer Res Clin Oncol 146(1):67-74. doi:10.1007/s00432-019-03084-x

22. Raz DJ, Gomez SL, Chang ET, Kim JY, Keegan TH, Pham J et al (2008) Epidemiology of non-small cell lung cancer in Asian Americans: incidence patterns among six subgroups by nativity. J Thorac Oncol 3(12):1391-1397. doi:10.1097/JT0.0b013e31818ddff7

23. Chougule A, Prabhash K, Noronha V, Joshi A, Thavamani A, Chandrani P et al (2013) Frequency of EGFR mutations in 907 lung adenocarcioma patients of Indian ethnicity. PLoS One 8(10):e76164. doi:10.1371/journal.pone.0076164

24. Shi Y, Au JS, Thongprasert S, Srinivasan S, Tsai CM, Khoa MT et al (2014) A prospective, molecular epidemiology study of EGFR mutations in Asian patients with advanced non-small-cell lung cancer of adenocarcinoma histology (PIONEER). J Thorac Oncol 9(2):154-162. doi:10.1097/JT0.0000000000000033

25. Zhou F, Zhou C (2018) Lung cancer in never smokers-the East Asian experience. Transl Lung Cancer Res 7(4):450-463. doi:10.21037/tlcr.2018.05.14

26. Toh CK, Gao F, Lim WT, Leong SS, Fong KW, Yap SP et al (2006) Never-smokers with lung cancer: epidemiologic evidence of a distinct disease entity. J Clin Oncol 24(15):2245-2251. doi:10.1200/JC0.2005.04.8033

27. Toh CK, Lim WT (2007) Lung cancer in never-smokers. J Clin Pathol 60(4):337-340. doi:10.1136/jcp.2006.040576

28. Koo LC, Ho JH (1990) Worldwide epidemiological patterns of lung cancer in nonsmokers. Int J Epidemiol 19(Suppl 1):S14-S23. doi:10.1093/ije/19.supplement_1.s14

29. Ou SH, Ziogas A, Zell JA (2009) Asian ethnicity is a favorable prognostic factor for overall survival in non-small cell lung cancer (NSCLC) and is independent of smoking status. J Thorac Oncol 4(9):1083-1093. doi:10.1097/JT0.0b013e3181b27b15

30. Martell BN, Garrett BE, Caraballo RS (2016) Disparities in Adult Cigarette Smoking - United States, 2002-2005 and 2010-2013. MMWR Morb Mortal Wkly Rep 65(30):753-758. doi:10.15585/mmwr.mm6530a1

31. Sun Y, Ren Y, Fang Z, Li C, Fang R, Gao B et al (2010) Lung adenocarcinoma from East Asian never-smokers is a disease largely defined by targetable oncogenic mutant kinases. J Clin Oncol 28(30):4616-4620. doi:10.1200/JC0.2010.29.6038

32. Wakelee HA, Chang ET, Gomez SL, Keegan TH, Feskanich D, Clarke CA et al (2007) Lung cancer incidence in never smokers. J Clin Oncol 25(5):472-478. doi:10.1200/JC0.2006.07.2983

33. Ha SY, Choi SJ, Cho JH, Choi HJ, Lee J, Jung K et al (2015) Lung cancer in never-smoker Asian females is driven by oncogenic mutations, most often involving EGFR. Oncotarget 6(7):5465-5474. doi:10.18632/oncotarget.2925

34. Santoro IL, Ramos RP, Franceschini J, Jamnik S, Fernandes AL (2011) Non-small cell lung cancer in never smokers: a clinical entity to be identified. Clinics 66(11):1873-1877. doi:10.1590/s1807-59322011001100005

35. Vu HA, Xinh PT, Ha HT, Hanh NT, Bach ND, Thao DT et al (2016) Spectrum of EGFR gene mutations in Vietnamese patients with non-small cell lung cancer. Asia Pac J Clin Oncol 12(1):86-90. doi:10.1111/ajco.12448

36. Wu YL, Zhong WZ, Li LY, Zhang XT, Zhang L, Zhou CC et al (2007) Epidermal growth factor receptor mutations and their correlation with gefitinib therapy in patients with non-small cell lung cancer: a meta-analysis based on updated individual patient data from six medical centers in mainland China. $J$ Thorac Oncol 2(5):430-439. doi:10.1097/01.JT0.0000268677.87496.4c

37. Kumar V, Becker K, Zheng HX, Huang Y, Xu Y (2015) The performance of NLST screening criteria in Asian lung cancer patients. BMC Cancer $15: 916$. doi:10.1186/s12885-015-1922-5

Page $11 / 12$ 
38. Aberle DR, Adams AM, Berg CD, Black WC, Clapp JD, Fagerstrom RM et al (2011) Reduced lung-cancer mortality with low-dose computed tomographic screening. N Engl J Med 365(5):395-409. doi:10.1056/NEJMoa1102873

\section{Figures}

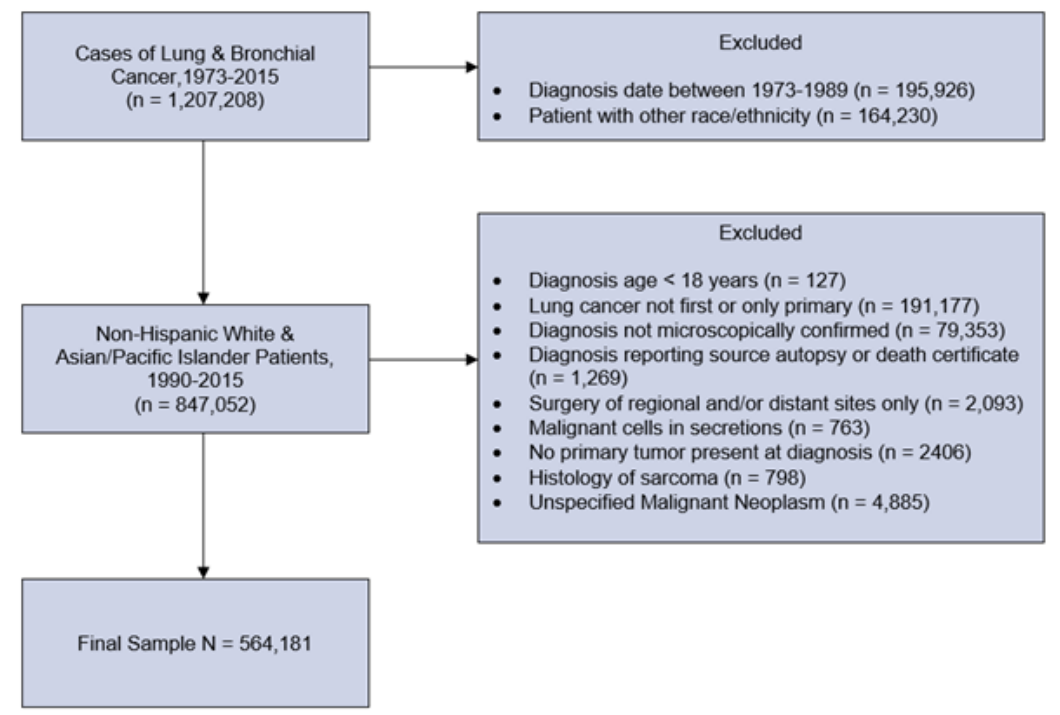

\section{Figure 1}

Selection criteria. 